\title{
Complementary and alternative medicine for the treatment of multiple sclerosis
}

\author{
Vijayshree Yadav $^{1, \dagger}$, Lynne Shinto ${ }^{1}$, and Dennis Bourdette ${ }^{1,2}$ \\ ${ }^{1}$ Department of Neurology L226, Oregon Health \& Science University, 3181 SW Sam Jackson Park \\ Road, Portland, OR 97239, USA \\ 2 Portland Veterans Affairs Medical Center, Portland, OR, USA
}

\begin{abstract}
Multiple sclerosis (MS) is a chronic disabling disease of the CNS that affects people during early adulthood. Despite several US FDA-approved medications, the treatment options in MS are limited. Many people with MS explore complementary and alternative medicine (CAM) treatments to help control their MS and treat their symptoms. Surveys suggest that up to 70\% of people with MS have tried one or more CAM treatment for their MS. People with MS using CAM generally report deriving some benefit from the therapies. The CAM therapies most frequently used include diet, omega- 3 fatty acids and antioxidants. There is very limited research evaluating the safety and effectiveness of CAM in MS. The most promising among CAM therapies that warrant further investigation are a low-fat diet, omega-3 fatty acids, lipoic acid and vitamin D supplementation as potential antiinflammatory and neuroprotective agents in both relapsing and progressive forms of MS. There is very limited research evaluating the safety and effectiveness of CAM in MS. However, in recent years, the NIH and the National MS Society have been actively supporting the research in this very important area.
\end{abstract}

\section{Keywords}

antioxidants; complementary and alternative medicine; dietary supplements; essential fatty acids; lipoic acid; low-fat diet; multiple sclerosis

\begin{abstract}
Multiple sclerosis (MS) is a chronic disabling disease of the CNS that affects approximately 500,000 people in the USA [1]. Most patients initially have a form of MS referred to as relapsing-remitting MS (RRMS). This type of MS is characterized by periods of clinical stability that are interrupted by relapses or attacks of MS during which patients experience clinical worsening. Patients may or may not have complete recovery from these relapses. Approximately $50 \%$ of patients with RRMS eventually enter a phase of the illness referred to as secondary progressive MS (SPMS), in which there is progressive worsening of their disease.
\end{abstract}

\footnotetext{
${ }^{\dagger}$ Author for correspondence: Tel.: +1 503494 5759, Fax: +1 503494 7289, yadavv@ ohsu.edu.

For reprint orders, please contact reprints@expert-reviews.com

Financial \& competing interests disclosure

Vijayshree Yadav has received personal compensation for activities with Biogen Idec as a speaker. Dennis Bourdette has received personal compensation for activities with Biogen Idec, EMD Serono, Pfizer Inc. and Teva Neurosciences as a speaker or faculty member. This study was supported by the National MS Society (PP0921 and CA 1055-A-3), the NIH (P50AT00066-01), the Department of Veterans Affairs and the Nancy Davis Center Without Walls. The authors have no other relevant affiliations or financial involvement with any organization or entity with a financial interest in or financial conflict with the subject matter or materials discussed in the manuscript apart from those disclosed.

No writing assistance was utilized in the production of this manuscript.
} 
Patients with SPMS often cease to have clinical relapses of MS. Approximately 10-15\% of people with MS have primary progressive MS (PPMS), in which there is progressive worsening of the neurologic symptoms from the onset of disease.

Multiple sclerosis pathogenesis is believed to involve an autoimmune response within the CNS, resulting in multifocal demyelination with varying axonal injury [1]. Inflammation and demyelination seem to be the primary pathology in the relapsing forms of MS, whereas neurodegeneration causing axonal degeneration seems to dominate the pathology in progressive forms of the disease [2]. The immune dysregulation in MS is primarily mediated by activated T cells, B cells and macrophages, as well as soluble mediators of inflammation such as antibodies, cytokines, free radicals and proteases. Transmigration of activated $\mathrm{T}$ cells across the blood-brain barrier is critical to the development of new inflammatory lesions in MS [1,3,4]. Several factors that facilitate T-cell migration across the blood-brain barrier include binding between integrins and their counter-ligands, such as ICAM-1 on endothelial cells and leukocyte function-associated antigen 1 on T cells and proteases produced by activated T cells, such as matrix metalloproteinase (MMP)-9 [5-13]. Several studies have reported higher MMP-9 levels in MS subjects compared with control subjects [14,15]. MS subjects with a relapsing-remitting disease course have been reported to have elevated MMP-9 mRNA levels expressed in immune cells compared with healthy controls [16]. Similarly, previous studies have correlated changes in serum MMP-9 activity with relapses of MS [17]. Cytokines also play important role as mediators of MS pathogenesis. Correlations exist between the expression of pro-inflammatory cytokines, such as TNF- $\alpha$, IFN- $\gamma$ and IL-2, during periods of clinical worsening and that of regulatory cytokines, such as IL-4 and IL-10, during periods of remission [18-24]. The currently available US FDA-approved disease-modifying therapies (DMTs) for MS, such as human recombinant IFN- $\beta$ and glatiramer acetate, work partly by shifting cytokine production from a proinflammatory to an anti-inflammatory profile [25-28]. In addition, IFN- $\beta$ also inhibits the MMP-9 levels and activity from the T cells [14, $29,30]$.

Treatments for MS are divided into two large categories: those that are intended to control the disease process and those that help to manage symptoms. Pharmacological agents that intend to control the disease process besides human recombinant IFN- $\beta$ and glatiramer acetate include a monoclonal antibody against $\alpha-4$ integrin, natalizumab and a chemotherapy agent, mitoxantrone. These therapies reduce the frequency of relapses and new lesion formation in the brain and reduce the risk of increased disability among patients with relapsing MS. However, these therapies are ineffective in progressive forms of MS, only partially effective in relapsing MS, only available in injectable forms, have significant side effects and are very costly.

Common symptoms that MS patients suffer from include fatigue, depression, cognitive impairment, spasticity, pain and imbalance. These symptoms can have a significant negative impact on the patient's quality of life; hence, treatment targeting these is critical.

Pharmacologic or rehabilitative treatments can help with these symptoms to a variable extent but care is still not optimal; therefore, the development of more effective and affordable symptomatic therapies remains a critical goal of MS care.

\section{Prevalence of complementary \& alternative medicine use in MS}

There have been a number of studies reporting the prevalence of complementary and alternative medicine (CAM) use by MS patients, and the range of prevalence is quite broad, at 33-70\% [31-39]. A conservative estimate from this range is that at least a third of MS patients have used CAM. Patient characteristics that are predictive of CAM use in MS are reported to be 
similar to those reported in the general population and include being female, being more highly educated and patient reports of poor health status $[31,33,34,36,40]$.

Most MS patients who use CAM report benefit from the commonly used therapies, which include diet, omega-3 fatty acids (FAs) and antioxidants [31,34,35,38,39]. In addition to the perceived benefit, reasons for CAM use include desire to use holistic health-care, patient empowerment, improving general health, and relief from physical and psychological symptoms $[31,32,34,41]$. The majority of MS patients use CAM as an adjunct to conventional therapies, rather than as an alternative to conventional MS therapies, and perceive both conventional and CAM therapies as being beneficial [31,32,34-37,39].

There is a paucity of well-designed clinical trials assessing the benefit of CAM therapies for treating MS. High-use therapies, which include diet, omega 3 FAs and antioxidants, may have potential benefit in MS as they have immunomodulatory and neuroprotective properties when evaluated in animal models, MS patients and in other chronic disease conditions. Diet, omega-3 FAs and antioxidants also appear to have a high safety profile when used at recommended doses. Table 1 provides a summary of CAM clinical trials in MS.

\section{Dietary supplements in MS}

\section{Omega-3 FAs}

Omega-3 FAs are a family of polyunsaturated FAs (PUFAs) that contain a common carboncarbon double bond at the third carbon from the terminal methyl end of the molecule. The parent omega-3 FA is linolenic acid. It is an 'essential fatty acid' and cannot be synthesized in humans and therefore must be supplied in the diet. Sources high in linolenic acid are plantbased and include flaxseeds and flaxseed oil, soy and soybean oil, and canola oil.

Eicosapentanoic acid (EPA) and docosahexanoic acid (DHA) are two omega-3 FAs that are synthesized from linolenic acid through a series of enzymatic steps [42]. While EPA and DHA can be synthesized from linolenic acid in humans, a rate-limiting enzymatic conversation from linolenic acid to EPA and DHA results in a very low conversion rate to EPA and DHA [43].

Unlike plant oils, which contain no EPA and DHA, fish and fish oils contain high levels of EPA and DHA, particularly coldwater fish (e.g., salmon and mackerel). DHA can cross the blood-brain barrier and, along with arachidonic acid, is a major component of neuronal cell membranes $[44,45]$. EPA can be converted to prostaglandin $\mathrm{I}_{3}$ and $\mathrm{E}_{3}$, thrombaxane $\mathrm{A}_{3}$ and leukotriene $\mathrm{B}_{5}$, and therefore has immunomodulatory capacity, acting as an anti-inflammatory agent $[42,46]$.

Although there are numerous studies reporting the immunomodulatory effects of omega-3 FAs, there are few studies evaluating omega-3 FAs in MS. Gallai et al. reported a significant decrease from baseline in the levels of the proinflammatory cytokines secreted from peripheral blood mononuclear cells (PBMCs) of MS subjects and healthy controls supplemented with fish oil [47]. Overall, 20 subjects with MS and 15 age-matched healthy controls were supplemented with $6 \mathrm{~g}$ per day of fish oil containing $3.0 \mathrm{~g}$ EPA and $1.8 \mathrm{~g}$ DHA for 3 months; the study also included a 2-month wash-out period. The significant decrease in PBMC-secreted cytokines was observed after 3 months of supplementation. All MS subjects had a stable course of MS for at least 3 months prior to enrollment, had not modified their diet as a consequence of developing MS and were not on any MS disease-modifying therapies. No differences were demonstrated in baseline ex vivo cytokine levels between MS subjects and controls. Cytokine levels were reported to have returned to baseline values in both groups after a 3-month washout period. 
Matrix metalloproteinase-9 appears to be important for T-cell migration into the CNS in MS and animal models of MS, and in vitro studies suggest that omega-3 FA supplementation can decrease MMP-9 production [48,49]. In an open-label pilot study, our group reported a significant decrease in MMP-9 levels secreted from unstimulated PBMCs [48]. Ten RRMS patients received fish oil concentrate at $8 \mathrm{~g}$ per day (containing $2.9 \mathrm{~g}$ EPA and $1.9 \mathrm{~g}$ DHA) for 3 months. All subjects showed a decrease in MMP-9 levels, whether or not they were on MS disease-modifying medication [48].

It is still not known exactly how omega-3 FAs decrease levels of MMP-9 and inflammatory cytokines. Omega-3 FAs have been reported to decrease NF- $\mathrm{\kappa B}$ and activator protein-1 binding activity, both of which may alter gene transcription of MMP-9 and some proinflammatory cytokines [49-51]. Therefore, modulating gene expression may be a mechanism by which omega-3 FAs might induce immunomodulation in MS. Future studies warrant evaluating the effects of EPA and DHA on MMP-9 mRNA levels.

There has been only one study evaluating the effects of omega-3 FA on MS disease activity [52]. This was a double-blind placebo-controlled trial in which MS patients $(\mathrm{n}=312)$ were randomized to receive either 20 capsules per day of either omega-3 FA (from fish oil) or an olive oil placebo for 2 years. The olive oil placebo contained $72 \%$ oleic acid and the fish oil contained a dose of EPA $1.71 \mathrm{~g}$ per day and DHA $1.41 \mathrm{~g}$ per day. This study reported a trend in improvement in the omega-3-treated subjects compared with controls in disease severity (measured by Expanded Disability Status Score [EDSS]) over 2 years $(\mathrm{p}=0.07)$. While the results did not achieve statistical significance favoring omega-3 FA supplementation, the study was not optimally designed. Both groups in the study were advised to follow a diet low in animal fat and high in omega-6 FAs. Importantly, both groups developed changes in serum FA content over the 2 years of the study, which may indicate a diet effect in the placebo group.

Omega-3 FAs appear to be safe. The Bates study did not report adverse effects of omega-3 or placebo oil supplementation over 2 years [52]. The published pilot studies conducted by our group support the safety of omega-3 FAs combined with MS disease-modifying therapies at a daily dose range of $2-8 \mathrm{~g}$ for 3-6 months [48,53]. No serious adverse effects were reported in either of these studies; any adverse events were mild. The Physician's Desk Reference for Nutritional Supplements reports no serious adverse events in those taking fish oil supplements up to $15 \mathrm{~g} /$ day [54]. The most common side effects are mild and include 'fishy burps' and mild gastrointestinal effects (e.g., stomach upset, loose stools/diarrhea and stomach bloating).

\section{Lipoic acid}

Lipoic acid (LA) is an antioxidant and dietary supplement that has a variety of biologic effects. LA is available in both oral and intravenous forms and is prescribed as a treatment for diabetic neuropathy in Germany. While some LA is derived from the diet, LA synthase can catalyze the generation of LA in mammals. Under normal circumstances, essentially no free LA is detectable within the blood. However, following oral or parenteral administration, free LA appears within the blood and a variety of tissues, including the CNS [55-57].

Lipoic acid and its reduced form, dihydrolipoic acid (DHLA), form a redox couple that functions as a cofactor for several mitochondrial dehydrogenases (Figure 1) [58]. In vitro, a number of anti-oxidant activities have been associated with LA/DHLA, including free radical scavenging, metallic ion chelation, regeneration of intracellular glutathione and repair of oxidative damage to macromolecules [59]. Extracellular LA enters the cell via the sodiumdependent multivitamin transport system and by diffusion across cell membranes.

Intracellularly, LA is reduced to DHLA within mitochondria by dihydrolipoyl dehydrogenase and in the cytoplasm by glutathione reductase and thioredoxin $[58,60,61]$. 
Several laboratories have shown that LA is an effective therapy in the animal model of MS, experimental autoimmune encephalomyelitis (EAE). EAE has provided important insights into the immunopathogenesis of MS and has led to the development of new therapeutic approaches for the treatment of MS $[62,63]$. LA has been shown to be an effective therapy for EAE [6466]. LA suppresses EAE by interfering with trafficking of encephalitogenic $T$ cells into the spinal cord. Immunomodulatory effects of LA involve several related mechanisms of action, including inhibition of MMP-9 production by T cells at the mRNA level and inhibition of the expression of the adhesion molecules ICAM-1 and VCAM-1 by CNS endothelial cells [64, 65,67]. Importantly, LA is able to stimulate production of cAMP via the prostaglandin receptors EP2 and EP4 [68,69]. cAMP is an important second messenger that activates protein kinase $\mathrm{A}$, initiating a cascade of effects that result in immunomodulation. This effect may be central to the therapeutic effect of LA in EAE.

We conducted a double-blind, placebo-controlled, dose-finding trial of orally administered LA in MS, which is the first reported trial of LA in MS and the first trial in humans to relate serum LA concentrations to changes in serum markers of inflammation [70]. This was a 2-week study with 37 subjects that, despite its short duration and small sample size, found that a dose of 1200 $\mathrm{mg}$ was significantly better than $600 \mathrm{mg}$ in producing measurable serum LA concentrations and was generally well tolerated. We also found that there was considerable inter-subject variability in peak serum LA concentrations determined by high-performance liquid chromatography (range $0-17 \mu \mathrm{g} / \mathrm{ml}$ with a $1200 \mathrm{mg}$ oral dose). In this study, we also explored the effect of oral LA administration on serum soluble ICAM-1 (sICAM-1) and MMP-9. A significant dose-response effect on serum sICAM-1 level also was observed with increasing doses of LA associated with decreasing levels of serum sICAM-1. We also found a statistically significant negative correlation between peak LA concentrations and changes in serum MMP-9 levels in this study, which considering the small sample size of the trial and the inter-subject variability in absorption of LA, supports the role of LA as potential anti-inflammatory agent. These observations provide the rationale for studying LA as a potential treatment for MS.

Lipoic acid appears to be safe and has been shown in randomized controlled trials to be effective for treating symptoms of diabetic polyneuropathy [71-77]. In these trials, the most common adverse reactions to LA included gastrointestinal intolerance, nausea and headache.

\section{Ginkgo biloba}

Ginkgo biloba (GB) is one of the traditional Chinese medicine treatments that has been used for centuries in China but has only recently gained popularity in the Western world.

Standardized extracts of GB leaves are available as supplement over the counter in the USA. GB extracts have a number of pharmacologic properties that suggest they may alter neural function and enhance cognitive performance. Flavonoids, which are primarily flavon-oglycosides, and terpenoids are the two major classes of compounds considered to be pharmacologically important in GB extracts. Standardized GB extracts typically contain approximately $24 \%$ flavonoids, $4-6 \%$ terpenoids and multiple other compounds in smaller quantities. The terpenoids are unique compounds only found in the Ginkgo tree and include bilobalide and the ginkgolides A, B, C, M and J. The flavon-o-glycosides are glycoside derivatives of quercetin, kaempferol and isorhamnetin [78].

Cognitive impairment can be a significant cause of morbidity and disability and can affect 40$50 \%$ of people with MS $[79,80]$. Currently, there are no effective symptomatic therapies for cognitive dysfunction in MS. GB has been suggested to improve cognitive performance in Alzheimer's disease, as seen in clinical trials and several other studies [81-86]. However, more recently, there have been negative trials on the effect of GB in dementia [87-90], which makes the issues of clinical efficacy of GB on cognition improvement somewhat more controversial. More recent systematic reviews that included results of these negative trials suggest that GB 
is safe but that the improvement on cognitive improvement appears to be inconsistent [91, 92], which contrasts with earlier systematic reviews [93].

Our group conducted a randomized placebo-controlled pilot study evaluating the effects of treatment with a standardized GB extract on cognitive performance in 43 subjects with MS [94]. Subjects received GB $120 \mathrm{mg}$ or placebo twice daily for 12 weeks. The outcomes of the study included several neuropsychological tests, including the Stroop test, which is a measure of attention and executive function. Subjects receiving GB showed improved performance on the Stroop test as well as improvement in subjective reports of cognitive deficits. This pilot study also showed that GB was safe and well tolerated. Based on these results, a double-blind placebo-controlled trial involving 100 subjects is underway to further assess the effects of GB on cognitive function in people with MS.

\section{Ginseng}

Fatigue is reported in $75-95 \%$ of people with MS, and 50-60\% of people with MS report that fatigue is their worst problem $[95,96]$. Treatment options for MS fatigue include the off-label use of CNS stimulants and amantadine. These medications are of limited efficacy, are often poorly tolerated and can be expensive. Ginseng may represent a novel approach to treating MS-related fatigue.

Ginseng is a herbal product that has been used in China for more than 2000 years. This compound is one of the most extensively studied herbal products in the scientific literature [97,98]. The known active constituents in American ginseng are the ginsenosides [99-102], which are reported to have a wide range of biological effects, including antioxidant activity with increased oxygen radical scavenging and decreased lipid peroxidation, stimulation of the hypothalamic-pituitary-adrenal system with a corticosteroidal effect, increased antitumor activity, improved cardiovascular function through vasodilation and reduced platelet aggregation, and hypoglycemic activity [103-110].

Despite uncertainty about its mechanism of action, a limited number of placebo-controlled trials have suggested that ginseng is capable of decreasing fatigue. Of particular interest, one placebo-controlled trial of 501 healthy adults with complaints of stress and fatigue demonstrated an overall improved quality of life after a 12-week treatment trial with an Asian ginseng extract [109]. Another large placebo-controlled trial of ginseng in 384 postmenopausal women with complaints of stress and fatigue demonstrated improved general wellbeing after 16 weeks of treatment [110].

Because ginseng appeared to be useful for fatigue in other populations, Kim et al. conducted a double-blind placebo-controlled crossover pilot trial of American ginseng extract using an escalating daily dose of $100 \mathrm{mg}, 200 \mathrm{mg}$ and $400 \mathrm{mg}$ for the first 3 weeks of a 6-week intervention period in subjects with MS to determine its effects on fatigue [111]. However, this study failed to show any benefit of American ginseng extract on fatigue in these subjects with MS [Kim E, Pers. Comm.]. Some subjects experienced insomnia while on American ginseng, suggesting that higher doses might not be tolerated. Thus, American ginseng does not appear to be a promising treatment for fatigue in MS.

Ginseng extracts appear to be safe, although large doses can cause side effects. Ginseng extracts have been used at doses of up to $2 \mathrm{~g}$ per day without adverse effects $[108,109]$. Excessive intake of ginseng (with dosing at 3-15 g per day) has been associated with hypertension, nervousness, irritability, insomnia, rash and diarrhea [112]. Five different animal models using conventional toxicological methods reported no acute or chronic toxicity of the extract $[97,113]$ 


\section{Green tea polyphenols (epigallocatechin-3-gallate)}

Epigallocatechin-3-gallate (EGCG) is one of the active constituents in green tea that has been reported to have immunomodulatory and neuroprotective effects in limited rodent models. In mouse models, EGCG has been reported to decrease TNF- $\alpha$ [114] and have neuroprotective effects in models of amyotrophic lateral sclerosis [115], Parkinson's disease [116] and transient ischemic artery occlusion [117].

One report evaluating EGCG in EAE found that to prevent disease, an oral dose of $300 \mu \mathrm{g}$ twice daily per mouse significantly reduced disease severity $(\mathrm{p}<0.05)$, while to treat disease, an effective dose was achieved at $60 \mu \mathrm{g}$ twice daily per mouse $(\mathrm{p}<0.05)$ [118].

Although there are no reports evaluating EGCG in MS patients, anti-inflammatory and neuroprotective effects in animal models of a variety of neurologic disorders warrant evaluation of EGCG for neuroprotection in MS. A clinical trial evaluating the safety and neuroprotective effects of EGCG in MS patients is currently underway at Louisiana State University (LA, USA) [Lovera J, Pers. Comm.]. EGCG will be given at a dose of $400 \mathrm{mg}$ twice daily for 2 years. The primary goal is to assess dose safety and to assess neuroprotection via MRI measures.

While EGCG is generally safe, there are reports of rare serious side effects. Daily doses between 400 and $2000 \mathrm{mg}$ have been evaluated in cancer studies $[119,120]$ and in obesity studies [121,122]; in these studies, EGCG has been reported to be well tolerated. Rare cases of liver failure have been reported with green tea extracts [123-125]. This side effect occurred within the first 50 days of starting the product and was reversible in most cases. The most commonly reported side effects are mild and include nausea, abdominal pain, headache and fatigue.

\section{Vitamin D}

Vitamin D is a group of fat-soluble prohormones, the two major forms of which are vitamin $\mathrm{D}_{2}$ (or ergocalciferol) and vitamin $\mathrm{D}_{3}$ (or cholecalciferol). In vertebrates, vitamin $\mathrm{D}_{3}$ is produced in the skin from exposure to UV radiation [126]. Vitamin $\mathrm{D}_{3}$ is converted into 25hydroxy-vitamin $\mathrm{D}_{3}$ in the liver and 1,25-dihydroxyvitamin $\mathrm{D}_{3}$ in the kidney [127]. 1,25dihydroxy-vitamin $\mathrm{D}_{3}$, which is the bioactive form of vitamin $\mathrm{D}$, is important for regulating the calcium and phosphorus levels in the blood by promoting their absorption from food and helping normal bone mineralization, growth and remodeling [128-130]. Vitamin D also regulates immune function (reviewed in $[131,132]$ ). There are emerging data that support the notion that vitamin D may have a potential immunomodulatory role in MS [133,134].

Epidemiologic studies have found that low vitamin D intake and low serum vitamin D levels may increase the risk of MS [135,136]. Earlier studies looking at serum vitamin D levels in MS and in healthy controls showed mixed results; however, more recent data support a high prevalence of vitamin D deficiency in people with MS. Barnes et al. reported no difference between MS matched controls in either serum vitamin $\mathrm{D}_{2}$ or $\mathrm{D}_{3}$ levels [137]. Van der Mei $e t$ $a l$. found no mean difference in serum vitamin $\mathrm{D}_{2}$ levels between MS patients and matched controls, but did find a significant correlation between increasing MS disability and low vitamin $\mathrm{D}_{2}$ levels [138]. Soilu-Hanninen et al. found no mean difference in serum vitamin $\mathrm{D}_{2}$ levels between MS subjects and controls during the winter months but found that MS subjects had significantly lower serum vitamin $\mathrm{D}_{2}$ levels than controls during the summer months [139]. This study also found that MS subjects had lower serum vitamin $\mathrm{D}_{2}$ levels during relapses compared with remission states. A recent study looked at the serum vitamin D levels in people with MS ( $\mathrm{n}=199)$ and found $84 \%$ of them to be vitamin D-deficient [140]. These authors also examined the change in serum vitamin D levels in $40 \mathrm{MS}$ patients who took either low-dose vitamin $\mathrm{D}_{2}(\leq 800 \mathrm{IU} /$ day $)$ or high-dose vitamin $\mathrm{D}_{3}(50,000 \mathrm{IU} /$ day for $7-10$ days, followed by 50,000 IU weekly or biweekly) and found that subjects in the high-dose vitamin $\mathrm{D}_{3}$ group had 
significantly elevated serum vitamin $\mathrm{D}$ levels compared with the low-dose vitamin $\mathrm{D}_{2}$ group. In an open-label study, oral calcitrol at a target dose of $2.5 \mu \mathrm{m} / \mathrm{dl}$ was found to be safe and tolerable in $16 \mathrm{MS}$ patient for up to 1 year of supplementation [141]. Another recent study examined the seasonal variation in the serum vitamin D levels in people with MS $(n=103)$ and healthy controls $(n=110)$ and found these levels to be significantly higher in summer than in winter in both people with MS and the healthy controls [142]. This study also suggested that women with higher circulating levels of vitamin D had a lower incidence of MS and MS-related disability.

One interesting study that examined whether vitamin $D$ has any effect on genetic susceptibility in MS found that the expression of the MS-associated MHC class II allele HLA-DRBI*1501 appears to be regulated by vitamin D [143]. This discovery may be an important clue towards the relationship between vitamin D and MS.

Studies of vitamin D in EAE, the animal model of MS, have shown that vitamin D inhibits inflammation. A low-calcium diet in conjunction with injection of 1,25-dihydroxy-vitamin $\mathrm{D}_{3}$ prolonged the survival of mice with severe EAE [144]. Cantorna et al. showed that 1,25dihydroxy-vitamin $\mathrm{D}_{3}$ completely eliminated signs of EAE in mice [145]. Subsequent studies indicated that 1,25-dihydroxy-vitamin $\mathrm{D}_{3}$ treatment resulted in a diminished presence of inflammatory macrophages in the inflamed CNS, suggesting that vitamin D may influence inflammatory cell trafficking or apoptosis [146].

Clinical trials looking at effects of vitamin D supplementation in people with MS are being conducted. One recent small study that included 29 people with RRMS correlated the levels of serum vitamin D with cytokines, IFN- $\gamma$ (considered proinflammatory) and IL-4 (considered anti-inflammatory) [147]. This study found that people with high serum vitamin D levels had an improved anti-inflammatory profile, thus suggesting a potential role of vitamin D in regulatory T-cell function in people with MS.

There are emerging data from both animal and small clinical trials that vitamin D may have potential beneficial effects in MS. The more specific role of vitamin D in MS management needs to be clarified in larger clinical trials.

\section{Cost of dietary supplements}

The costs of the dietary supplements discussed will vary depending on dose and brand, and in the USA, dietary supplements are not covered by insurance and therefore it is an out-of-pocket cost for patients. The cost of each individual supplement is relatively inexpensive, ranging from US\$20 to 40 per month.

\section{Cannabis}

There have been a number of studies evaluating the use cannabinoids in people with MS. As the majority of controlled studies have evaluated cannabinoids for spasticity in MS, we will focus on these studies.

The major psychoactive constituent in cannabis is $\delta$-9-tetrahydrocannabinol (THC). THC binds to cannabinoid receptors (CBs) in the CNS and acts as a partial agonist to both $\mathrm{CB}_{1}$ and $\mathrm{CB}_{2}$ receptors. In MS, the mechanism of action of THC is unknown, although there is limited evidence that it has anti-inflammatory and neuroprotective properties [148].

Cannabidol (CBD) is a non-psychoactive constituent in cannabis and is the major constituent in the plant. It is thought to decrease the clearance of THC by affecting liver metabolism. It binds to both $\mathrm{CB}_{1}$ and $\mathrm{CB}_{2}$ receptors in the $\mathrm{CNS}$, with a higher affinity to the $\mathrm{CB}_{2}$ receptor. 
In a review of six controlled studies evaluating a combination of THC and CBD for spasticity in MS, it was found that THC-CBD was well tolerated and improved patient self-reports of spasticity [149-155]. Objective measures did not show significant improvement compared with placebo [149]. Three of the six studies were placebo-controlled; the sample size range was 12-295 MS patients; the dose range was less than $10 \mathrm{mg} /$ day to $120 \mathrm{mg} /$ day; and the intervention range was $2-15$ weeks $[152,153,155]$. Only one study reported a significant improvement in Ashworth score [154] and none of the studies reported a significant improvement in timed walk. The authors noted that side effects were mild and reported in both treatment and placebo groups. The authors concluded that there was significant improvement in patient-reported spasticity combined and that the combination of THC and CBD was well tolerated in MS. They noted that objective measures of spasticity showed no significant improvement.

Unlike the dietary supplements discussed, THC is a controlled substance (requiring a prescription in the USA) and is sold under the trade name of Marinol ${ }^{\circledR}$ (Solvay Pharmaceuticals, IL, USA).

\section{MS \& diet}

The role of diet in both causing and ameliorating the severity of MS has intrigued people with MS and researchers alike. The relationship between dietary habits and MS has been explored most famously by Roy Swank, a US neurologist in the 1950s-1980s who advocated significant dietary modification in people with MS. The 'Swank diet' he devised is characterized by intake of a very low amount of saturated fats (no more than 10-15 g/day). In addition, people are advised to take cod liver (fish) oil supplementation, a major source of omega-3 FAs. Before the introduction of disease-modifying therapies in the mid-to-late 1990s, the 'Swank diet' was widely used by MS patients and is still followed by many patients today [156]. Observational studies published between 1953 and 2003 by Swank suggested that patients who follow a diet low in total fats and saturated fats have reduced MS disease activity and disability progression compared with those not following a low-fat diet [157-161]. The 50-year study that began in 1953 looked at the effects of the Swank diet in MS and provided follow-up information for 144 MS patients and demonstrated their survival [160]. In this study, MS patients were divided into two groups: 'good dieters' $(\mathrm{n}=70)$ and 'bad dieters' $(\mathrm{n}=74)$. The good dieters strictly followed a low-fat diet by consuming less than $20 \mathrm{~g} / \mathrm{day}$ of fat and bad dieters consumed more than $20 \mathrm{~g}$ /day of fat. After 34 years, there had been 23 deaths in the good dieters group as compared with 58 deaths in the bad dieters group. After a period of 15 years during which subjects were not followed, investigators contacted the subjects again in the year 2000 and found only 15 survivors, all of which were from the good dieters group. Most of these patients (13 out of 15) were still ambulatory and found to be otherwise healthy MS patients. This study, although it is a unique long-term follow-up of an intervention for MS, has been criticized for the lack of a control group for comparison [162].

A small, 1-year, partially blinded randomized trial studied the effect of low-fat dietary intervention with omega-3 FA supplementation in 31 RRMS subjects [163]. Subjects were randomized into one of two groups: the 'fish oil' group and the 'olive oil' group. The 'fish oil' group was given a low-fat diet consisting of FAs from fish oil supplementation intake, not exceeding $15 \%$ of total daily calories. These subjects also took six fish oil capsules (equivalent to $1 \mathrm{~g}$ of fish oil; containing 65\% omega-3 FAs; EPA $1.98 \mathrm{~g} /$ day and DHA $1.32 \mathrm{~g} / \mathrm{day}$ ). The 'olive oil' group received olive oil supplements (six capsules of $1 \mathrm{~g}$ of olive oil per day) and followed the American Heart Association Step I diet (total fat $\leq 30 \%$ of total daily calories and saturated fats $<10 \%$ of total daily calories). The primary outcome of the study was the Physical Component Scale of the Short-Form Health Survey Questionnaire. Secondary outcomes were the Modified Fatigue Impact Scale and Mental Health Inventory. The subjects were followed 
for an average of $11 \pm 2.9$ months and the fish oil group maintained higher Physical Component Scale scores than the olive oil supplementation group (although this was not statistically significant). The MHI scores were similar in the two intervention groups. At the 6-month time point, the olive oil group reported reduced fatigue as compared with the fish oil group ( $\mathrm{p}=$ 0.035), which continued for 12 months. For both intervention groups, relapse rates were reduced compared with the year prior to entering the study. This study therefore suggested that a low saturated fat diet with fish oil supplementation might promote better physical and mental health for people with MS.

Another 2-year, open-label uncontrolled study examined the effects of dietary advice along with fish oil and vitamin supplementation in 16 newly diagnosed MS patients (four men and 12 women; mean age: 32 years; mean duration of MS: 1.6 years) [164]. The outcomes of the study included annual MS exacerbation rate and disability as measured by EDSS [164]. The intervention included increased fish intake (up to three to four times per week) along with vegetables and fruits daily, while reducing saturated fat intake from meats and dairy products, as well as sugar-containing products. The subjects received a vitamin B complex and $200 \mathrm{mg}$ of vitamin $\mathrm{C}$ supplementation in addition to $5 \mathrm{ml}$ of fish oil (containing $0.4 \mathrm{~g}$ of EPA, $0.5 \mathrm{~g}$ of DHA, $1.0 \mathrm{mg}$ of vitamin A, $10 \mu \mathrm{g}$ of vitamin D and $5.5 \mathrm{mg}$ of vitamin E). After 2 years of the study intervention, there was a significant reduction in the mean annual exacerbation rate (prestudy rate: 1.39 , decreased to $0.06 ; \mathrm{p}<0.001$ ) and EDSS (pre-study score: 2.16 , decreased to $1.63 ; \mathrm{p}<0.01$ ). There was also a significant change in the blood lipid profile as evident by an increase in the plasma total phospholipid omega-3 FA levels and decrease in the omega-6 FA levels. Even though the reduction in relapse rate and improvement in EDSS were remarkable for an open-label study, the trial is limited by the lack of a control group and not being randomized or blinded. The positive study results are also criticized as possibly being due to physiologic placebo effects and that results could represent 'regression towards the mean.'

A case-controlled 4-year study of 197 MS patients and 202 matched-control subjects examined the association between different dietary factors and the risk of MS [165]. This study shows support for a possible protective function against MS risk of the components frequently found in plants, such as vegetable protein and dietary fiber (especially from cereals), vitamin C, thiamine, riboflavin, calcium and potassium. This study also showed a significant positive relationship of a high-energy-intake diet and high animal fat consumption with the possibility of developing MS. At least two other researchers have examined the connection between nutrition and MS and found a significant prevalence of malnutrition in the disease. These authors recommend initiating healthy eating habits after diagnosis of MS [166,167].

These publications on the potential therapeutic effects of a low-fat diet and omega-3 FA supplementation certainly have methodological problems and are not definitive. However, given the low cost and safety of a low-fat diet and fish oil supplementation, these studies provide additional impetus for performing larger and better-designed trials. However, this approach to treating MS has never been subjected to a well-controlled clinical trial and consequently most physicians are unlikely to make dietary recommendations to people with MS.

\section{Expert commentary}

There is a great divide between people with MS and most conventional physicians over the issue of CAM therapies. Most people with MS try CAM approaches and many continue to use them in an effort to improve the quality of their lives. For certain CAM therapies, MS patients report benefit, enough so to continue taking them and to pay for them themselves. However, most conventional physicians discourage patients from pursuing CAM therapies, partly owing to the absence of scientific evidence of their benefit and partly owing to concerns over patients pursuing costly and potentially risky therapies. Most CAM therapies have not been studied in 
well-designed clinical trials and as a known limitation of small pilot studies, most clinical trials published thus far are not adequately powered to assess the desired outcome. However, the absence of evidence does not mean absence of benefit. In addition, surveys reveal that most people with MS are trying safe and relatively low-cost CAM therapies. The challenge is to identify CAM therapies that have some rationale for benefit and to conduct well-designed clinical trials to determine what works and what does not.

We believe that certain CAM therapies, particularly dietary supplements, have sufficient evidence from in vitro and animal studies to warrant investigation. As outlined in this review, there is ample evidence to justify investigations of omega-3 FAs and LA as disease-modifying therapies for MS. Other supplements, such as GB, might prove useful as symptomatic therapies for MS. Cannabis shows evidence from patient self-reports to improve spasticity, although this is not a dietary supplement and requires a prescription in the USA. Dietary supplements have the advantage of being amenable to double-blind placebo-controlled trials, which allows for screening of these therapies in pilot trials. The negative pilot trial of American ginseng extract for fatigue in MS and the positive pilot trial of GB for cognitive impairment in MS have allowed investigators to pursue one, GB, in a larger trial and conclude that the other, American ginseng, is not effective.

Dietary supplements that prove beneficial in MS offer opportunities for development and improvement for the pharmaceutical industry. LA is highly effective in the animal model of MS; however, it is erratically absorbed when taken orally by humans and this may prove to be a significant obstacle to its use as a treatment for MS. Developing formulations or derivatives of LA that are reliably absorbed from the GI tract would help in the development of LA as a treatment for MS and other disorders. Botanical extracts, such as GB, contain a variety of biologically active compounds. Should GB prove to be effective as a symptomatic therapy for cognitive impairment in MS, identifying the chemical constituents that are responsible for the positive effects could lead to further drug development.

In general, we recommend that healthcare providers have an open-minded approach to people with MS using CAM therapies. People with MS who use CAM therapies are generally wellinformed and use CAM therapies that are safe. In our MS clinics, we encourage the use of disease-modifying agents as the first-line therapy for relapsing MS management, but emphasize an overall wellness approach for all MS patients. This wellness approach includes the use of CAM therapies such as a low-fat diet, supplementation with omega 3-FAs and vitamin $\mathrm{D}$, as well as the use of mind and body techniques such as yoga, tai'chi and prayer. We also work closely with an MS-trained naturopath physician and acupuncturist to offer additional guidance to patients who are more inclined towards a holistic approach towards their disease. In our experience, most people who have adopted this wellness approach to their MS care report improvement in their sense of wellbeing and quality of life. It is of course uncertain whether these approaches alter disease activity. We strongly discourage people with MS to indulge in expensive CAM therapies without clear benefit or those that may potentially be toxic. Health professionals can also educate themselves as well as counsel their patients by utilizing information about CAM therapies from resources such as the National MS Society and the NIH, especially the National Center of Complementary and Alternative Medicine websites and publications.

\section{Five-year view}

Assessing the effectiveness of any therapy for MS takes several years. For CAM therapies that might alter the disease course, screening therapies in the animal model of MS, EAE, is a costeffective way of determining whether a CAM therapy is worth pursuing in clinical trials. CAM therapies might be useful as symptomatic therapies, however, will require the conduction of

Expert Rev Clin Immunol. Author manuscript; available in PMC 2011 March 1. 
well-designed double-blind placebo-controlled pilot trials. We anticipate that over the next 5 years we will see more trials of CAM therapies, both in EAE and in pilot trials in MS.

At present, the approaches that appear to hold the most promise and warrant further investigation in MS are:

- The effectiveness of a low-fat diet in relapsing MS

- The effectiveness of omega-3 FA and LA supplementation as anti-inflammatory and neuroprotective agents in both relapsing and progressive forms of MS

- The role of vitamin D as an anti-inflammatory and neuroprotective agent in MS

Within 5 years, large double-blind placebo-controlled trials of GB for cognitive impairment in MS will have been completed and we will know whether or not this is effective.

\section{Key issues}

- Conservative estimates are that at least a third of multiple sclerosis (MS) patients use complementary and alternative medicine (CAM) therapies.

- While the majority of MS patients who use CAM report benefit from diet, omega-3 fatty acids (FAs) and antioxidant supplements, these treatments have not been investigated with the rigor required to determine whether or not they are effective.

- There is evidence to support investigating the effectiveness of omega-3 FAs as an anti-inflammatory and neuroprotective therapy for MS.

- Lipoic acid (LA) is an antioxidant that has been shown to be effective in treating the animal model of MS, experimental autoimmune encephalomyelitis. Early clinical trials of LA in MS suggest that it can modulate some immunologic markers associated with disease activity, however, LA is erratically absorbed when taken orally. Further studies in MS are warranted.

- Ginkgo biloba may improve cognitive performance in MS but a larger clinical trial, which is currently underway, needs to be completed to prove its efficacy.

- American ginseng extract is ineffective in treating fatigue in MS.

- Vitamin D deficiency appears to increase the risk of developing MS. Results from large clinical trials are needed to determine whether vitamin D supplementation is a potential treatment for MS.

- Cannabis may improve spasticity in MS, although most trials show improvements in patient self-report and not in objective measures of spasticity (Ashworth).

- A low-fat diet deserves investigation as an adjunctive therapy for the control of relapsing MS.

\section{References}

Papers of special note have been highlighted as:

- of interest

1. Noseworthy J, Lucchinetti C, Rodriguez M, Weinshenker B. Multiple sclerosis. N Engl J Med 2000;343:938-952. [PubMed: 11006371]

2. Bjartmar C, Wujek JR, Trapp BD. Axonal loss in the pathology of MS: consequences for understanding the progressive phase of the disease. J Neurol Sci 2003;206:165-171. [PubMed: 12559505] 
3. Prat A, Al-Asmi A, Duquette P, Antel JP. Lymphocyte migration and multiple sclerosis: relation with disease course and therapy. Ann Neurol 1999;46:253-256. [PubMed: 10443892]

4. Martino G, Hartung HP. Immunopathogenesis of multiple sclerosis: the role of T cells. Curr Opin Neurol 1999;12:309-321. [PubMed: 10499176]

5. Dietrich J, Menne C, Lauritsen JP, et al. Ligand-induced TCR down-regulation is not dependent on constitutive TCR cycling. J Immunol 2002;168:5434-5440. [PubMed: 12023336]

6. Rieckmann P, Altenhofen B, Riegel A, Kallmann B, Felgenhauer K. Correlation of soluble adhesion molecules in blood and cerebrospinal fluid with magnetic resonance imaging activity in patients with multiple sclerosis. Mult Scler 1998;4:178-182. [PubMed: 9762670]

7. Khoury SJ, Orav EJ, Guttmann CR, Kikinis R, Jolesz FA, Weiner HL. Changes in serum levels of ICAM and TNF-R correlate with disease activity in multiple sclerosis. Neurology 1999;53:758-764. [PubMed: 10489037]

8. Giovannoni G, Miller DH, Losseff NA, et al. Serum inflammatory markers and clinical/MRI markers of disease progression in multiple sclerosis. J Neurol 2001;248:487-495. [PubMed: 11499639]

9. Liuzzi GM, Trojano M, Fanelli M, et al. Intrathecal synthesis of matrix metalloproteinase-9 in patients with multiple sclerosis: implication for pathogenesis. Mult Scler 2002;8:222-228. [PubMed: 12120694]

10. Leppert D, Lindberg RL, Kappos L, Leib SL. Matrix metalloproteinases: multifunctional effectors of inflammation in multiple sclerosis and bacterial meningitis. Brain Res Brain Res Rev 2001;36:249-257. [PubMed: 11690622]

11. Hartung HP, Kieseier BC. The role of matrix metalloproteinases in autoimmune damage to the central and peripheral nervous system. J Neuroimmunol 2002;107:140-147. [PubMed: 10854648]

12. Cuzner ML, Opdenakker G. Plasminogen activators and matrix metalloproteases, mediators of extracellular proteolysis in inflammatory demyelination of the central nervous system. $\mathrm{J}$ Neuroimmunol 1999;94:1-14. [PubMed: 10376931]

13. Madri JA, Graesser D. Cell migration in the immune system: the evolving inter-related roles of adhesion molecules and proteinases. Dev Immunol 2000;7:103-116. [PubMed: 11097205]

14. Trojano M, Avolio C, Liuzzi GM, et al. Changes of serum sICAM-1 and MMP-9 induced by rIFN $\beta-1 b$ treatment in relapsing-remitting MS. Neurology 1999;53:1402-1408. [PubMed: 10534242]

15. Waubant E, Goodkin DE, Gee L, et al. Serum MMP-9 and TIMP-1 levels are related to MRI activity in relapsing multiple sclerosis. Neurology 1999;53:1397-1401. [PubMed: 10534241]

16. Bar-Or A, Nuttall RK, Duddy M, et al. Analyses of all matrix metalloproteinase members in leukocytes emphasize monocytes as major inflammatory mediators in multiple sclerosis. Brain 2003;126:2738-2749. [PubMed: 14506071]

17. Leppert D, Ford J, Stabler G, et al. Matrix metalloproteinase-9 (gelatinase B) is selectively elevated in CSF during relapses and stable phases of multiple sclerosis. Brain 1998;121(Pt 12):2327-2334. [PubMed: 9874483]

18. Misu T, Fujihara K, Itoyama Y. Chemokines and chemokine receptors in multiple sclerosis. Nippon Rinsho 2003;61:1422-1427. [PubMed: 12962033]

19. Hartung HP, Archelos JJ, Zielaset J, et al. Circulating adhesion molecules and inflammatory mediators in demyelination: a review. Neurology 1995;45:S22-S32. [PubMed: 7783908]

20. Rudick RA, Ransohoff RM. Cytokine secretion by multiple sclerosis monocytes. Relationship to disease activity. Arch Neurol 1992;49:265-270. [PubMed: 1536629]

21. Sharief MK, Hentges R. Association between tumor necrosis factor- $\alpha$ and disease progression in patients with multiple sclerosis. N Engl J Med 1991;325:467-472. [PubMed: 1852181]

22. Hauser SL, Doolittle TH, Lincoln R, Brown RH, Dinarello CA. Cytokine accumulations in CSF of multiple sclerosis patients: frequent detection of interleukin-1 and tumor necrosis factor but not interleukin-6. Neurology 1990;40:1735-1739. [PubMed: 2234430]

23. Trotter JL, Collins KG, van der Veen RC. Serum cytokine levels in chronic progressive multiple sclerosis: interleukin-2 levels parallel tumor necrosis factor- $\alpha$ levels. J Neuroimmunol 1991;33:29_ 36. [PubMed: 2056069]

24. Hofman FM, Hinton DR, Johnson K, Merrill JE. Tumor necrosis factor identified in multiple sclerosis brain. J Exp Med 1989;170:607-612. [PubMed: 2754393]

Expert Rev Clin Immunol. Author manuscript; available in PMC 2011 March 1. 
25. Duda PW, Schmied MC, Cook SL, Krieger JI, Hafler DA. Glatiramer acetate (Copaxone) induces degenerate, Th2-polarized immune responses in patients with multiple sclerosis. J Clin Invest 2000;105:967-976. [PubMed: 10749576]

26. Miller A, Shapiro S, Gershtein R, et al. Treatment of multiple sclerosis with copolymer-1 (Copaxone): implicating mechanisms of Th1 to Th2/Th3 immune-deviation. J Neuroimmunol 1998;92:113-121. [PubMed: 9916886]

27. Neuhaus O, Farina C, Yassouridis A, et al. Multiple sclerosis: comparison of copolymer-1-reactive $\mathrm{T}$ cell lines from treated and untreated subjects reveals cytokine shift from $\mathrm{T}$ helper 1 to $\mathrm{T}$ helper 2 cells. Proc Natl Acad Sci USA 2000;97:7452-7457. [PubMed: 10861011]

28. Yong VW, Krekoski CA, Forsyth PA, Bell R, Edwards DR. Matrix metalloproteinases and diseases of the CNS. Trends Neurosci 1998;21:75-80. [PubMed: 9498303]

29. Leppert D, Waubant E, Burk MR, Oksenberg JR, Hauser SL. Interferon $\beta$-1b inhibits gelatinase secretion and in vitro migration of human T cells: a possible mechanism for treatment efficacy in multiple sclerosis. Ann Neurol 1996;40:846-852. [PubMed: 9007089]

30. Stuve O, Dooley NP, Uhm JH, et al. Interferon $\beta$-1b decreases the migration of T lymphocytes in vitro: effects on matrix metalloproteinase-9. Ann Neurol 1996;40:853-863. [PubMed: 9007090]

31. Berkman C, Pignotti M, Cavallo P, Holland N. Use of alternative treatments by people with multiple sclerosis. Neurorehabil Neural Repair 1999;13:243-254.

32. Leong EM, Semple SJ, Angley M, Siebert W, Petkov J, McKinnon RA. Complementary and alternative medicines and dietary interventions in multiple sclerosis: what is being used in South Australia and why? Complement Ther Med 2009;17:216-223. [PubMed: 19632549]

33. Marrie RA, Hadjimichael O, Vollmer T. Predictors of alternative medicine use by multiple sclerosis patients. Mult Scler 2003;9:461-466. [PubMed: 14582770]

34. Nayak S, Matheis RJ, Schoenberger NE, Shiflett SC. Use of unconventional therapies by individuals with multiple sclerosis. Clin Rehabil 2003;17:181-191. [PubMed: 12625659]

35. Page SA, Verhoef MJ, Stebbins RA, Metz LM, Levy JC. The use of complementary and alternative therapies by people with multiple sclerosis. Chronic Dis Can 2003;24:75-79. [PubMed: 12959678]

36. Schwartz CE, Laitin E, Brotman S, LaRocca N. Utilization of unconventional treatments by persons with MS: is it alternative or complementary? Neurology 1999;52:626-629. [PubMed: 10025800]

37. Schwarz S, Knorr C, Geiger H, Flachenecker P. Complementary and alternative medicine for multiple sclerosis. Mult Scler 2008;14:1113-1119. [PubMed: 18632773]

38. Stuifbergen AK, Harrison TC. Complementary and alternative therapy use in persons with multiple sclerosis. Rehabil Nurs 2003;28:141-147. 158. [PubMed: 14521002]

39. Yadav V, Shinto L, Morris C, Senders A, Baldauf-Wagner S, Bourdette D. Use and self reported benefit of complementary and alternative medicine (CAM) among multiple sclerosis patients. Int J MS Care 2006;8:5-10.

40. Shinto L, Yadav V, Morris C, Lapidus JA, Senders A, Bourdette D. Demographic and health-related factors associated with complementary and alternative medicine (CAM) use in multiple sclerosis. Mult Scler 2006;12:94-100. [PubMed: 16459725]

41. Shinto L, Yadav V, Morris C, Lapidus JA, Senders A, Bourdette D. The perceived benefit and satisfaction from conventional and complementary and alternative medicine (CAM) in people with multiple sclerosis. Complement Ther Med 2005;13:264-272. [PubMed: 16338197]

42. Fetterman JW Jr, Zdanowicz MM. Therapeutic potential of n-3 polyunsaturated fatty acids in disease. Am J Health Syst Pharm 2009;66:1169-1179. [PubMed: 19535655]

43. Arterburn LM, Hall EB, Oken H. Distribution, interconversion, and dose response of n-3 fatty acids in humans. Am J Clin Nutr 2006;83:1467S-1476S. [PubMed: 16841856]

44. Lim SY, Suzuki H. Effect of dietary docosahexaenoic acid and phosphatidylcholine on maze behavior and fatty acid composition of plasma and brain lipids in mice. Int J Vitam Nutr Res 2000;70:251259. [PubMed: 11068705]

45. Tinoco J. Dietary requirements and functions of $\alpha$-linolenic acid in animals. Prog Lipid Res 1982;21:1-45. [PubMed: 6287500]

46. Calder PC. Dietary modification of inflammation with lipids. Proc Nutr Soc 2002;61:345-358. [PubMed: 12296294] 
47. Gallai V, Sarchielli P, Trequattrini A, et al. Cytokine secretion and eicosanoid production in the peripheral blood mononuclear cells of MS patients undergoing dietary supplementation with n-3 polyunsaturated fatty acids. J Neuroimmunol 1995;56:143-153. [PubMed: 7860710]

48•. Shinto L, Marracci G, Baldauf-Wagner S, et al. Omega-3 fatty acid supplementation decreases matrix metalloproteinase-9 production in relapsing-remitting multiple sclerosis. Prostaglandins Leukot Essent Fatty Acids 2009;80:131-136. Open-label study evaluating omega-3 fatty acid (FA) in multiple sclerosis (MS) found a significant reduction in immune cell-secreted matrix metalloproteinase (MMP)-9 levels after 3 months of omega-3 FA supplementation. All ten subjects had a reduction in MMP-9 levels, whether or not on MS disease-modifying therapy. [PubMed: 19171471]

49. St-Pierre Y, Van Themsche C, Esteve PO. Emerging features in the regulation of $M M P-9$ gene expression for the development of novel molecular targets and therapeutic strategies. Curr Drug Targets Inflamm Allergy 2003;2:206-215. [PubMed: 14561155]

50. Zhao G, Etherton TD, Martin KR, et al. Anti-inflammatory effects of polyunsaturated fatty acids in THP-1 cells. Biochem Biophys Res Commun 2005;336:909-917. [PubMed: 16169525]

51. Zhao Y, Chen LH. Eicosapentaenoic acid prevents lipopolysaccharide-stimulated DNA binding of activator protein-1 and c-Jun N-terminal kinase activity. J Nutr Biochem 2005;16:78-84. [PubMed: 15681165]

52. Bates D, Cartlidge N, French JM, et al. A double-blind controlled trial of long chain n-3 polyunsaturated fatty acids in the treatment of multiple sclerosis. J Neurol Neurosurg Psychiatry 1989;52:18-22. Double-blind placebo-controlled trial evaluating omega-3 FA in MS ( $\mathrm{n}=312$ ) showed a trend favoring the omega-3 FA group in improvement in MS disability over 2 years. [PubMed: 2540285]

53. Shinto L, Calabrese C, Morris C, et al. A randomized pilot study of naturopathic medicine in multiple sclerosis. J Altern Complement Med 2008;14:489-496. [PubMed: 18532899]

54. Hendler, SS.; Rorvik, D., editors. PDR for Nutritional Supplements. 1. Thomson Healthcare; NJ, USA: 2001.

55. Peter G, Borbe HO. Absorption of [7,8-14C]rac-a-lipoic acid from in situ ligated segments of the gastrointestinal tract of the rat. Arzneimittelforschung 1985;45:293-299. [PubMed: 7741788]

56. Harrison EH, McCormick DB. The metabolism of dl-(1,6-14C) lipoic acid in the rat. Arch Biochem Biophys 1974;160:514-522. [PubMed: 4598618]

57. Packer L, Roy S, Sen CK. $\alpha$-lipoic acid: a metabolic antioxidant and potential redox modulator of transcription. Adv Pharmacol 1997;38:79-101. [PubMed: 8895805]

58. Biewenga GP, Dorstijn MA, Verhagen JV, Haenen GR, Bast A. Reduction of lipoic acid by lipoamide dehydrogenase. Biochem Pharmacol 1996;51:233-238. [PubMed: 8573188]

59. Biewenga GP, Haenen GR, Bast A. The pharmacology of the antioxidant lipoic acid. Gen Pharmacol 1997;29:315-331. [PubMed: 9378235]

60. Arner ES, Nordberg J, Holmgren A. Efficient reduction of lipoamide and lipoic acid by mammalian thioredoxin reductase. Biochem Biophys Res Commun 1996;225:268-274. [PubMed: 8769129]

61. Pick U, Haramaki N, Constantinescu A, Handelman GJ, Tritschler HJ, Packer L. Glutathione reductase and lipoamide dehydrogenase have opposite stereospecificities for $\alpha$-lipoic acid enantiomers. Biochem Biophys Res Commun 1995;206:724-730. [PubMed: 7826393]

62. Yednock TA, Cannon C, Fritz LC, Sanchez-Madrid F, Steinman L, Karin N. Prevention of experimental autoimmune encephalomyelitis by antibodies against $\alpha 4 \beta 1$ integrin. Nature 1992;356:63-66. [PubMed: 1538783]

63. Tubridy N, Behan PO, Capildeo R, et al. The effect of anti- $\alpha 4$ integrin antibody on brain lesion activity in MS. The UK Antegren Study Group. Neurology 1999;53:466-472. [PubMed: 10449105]

64. Marracci GH, Jones RE, McKeon GP, Bourdette DN. $\alpha$ lipoic acid inhibits T cell migration into the spinal cord and suppresses and treats experimental autoimmune encephalomyelitis. J Neuroimmunol 2002;131:104-114. [PubMed: 12458042]

65. Morini M, Roccatagliata L, Dell'Eva R, et al. $\alpha$-lipoic acid is effective in prevention and treatment of experimental autoimmune encephalomyelitis. J Neuroimmunol 2004;148:146-153. [PubMed: 14975595] 
66. Schreibelt G, Musters RJ, Reijerkerk A, et al. Lipoic acid affects cellular migration into the central nervous system and stabilizes blood-brain barrier integrity. J Immunol 2006;177:2630-2637. [PubMed: 16888025]

67. Marracci GH, McKeon GP, Marquardt WE, Winter RW, Riscoe MK, Bourdette DN. $\alpha$ lipoic acid inhibits human T-cell migration: implications for multiple sclerosis. J Neurosci Res 2004;78:362370. [PubMed: 15389837]

68. Schillace RV, Pisenti N, Pattamanuch N, et al. Lipoic acid stimulates cAMP production in T lymphocytes and NK cells. Biochem Biophys Res Commun 2007;354:259-264. [PubMed: 17210133]

69. Salinthone S, Schillace RV, Marracci GH, Bourdette DN, Carr DW. Lipoic acid stimulates cAMP production via the EP2 and EP4 prostanoid receptors and inhibits IFN $\gamma$ synthesis and cellular cytotoxicity in NK cells. J Neuroimmunol 2008;199:46-55. [PubMed: 18562016]

70•. Yadav V, Marracci G, Lovera J, et al. Lipoic acid in multiple sclerosis: a pilot study. Mult Scler 2005;11:159-165. Pilot study evaluating effects of oral lipoic acid (LA) in MS. Suggested that oral LA may have immunological effects in MS. [PubMed: 15794388]

71. Ziegler D, Hanefeld M, Ruhnau K, et al. Treatment of symptomatic diabetic peripheral neuropathy with the anti-oxidant $\alpha$-lipoic acid. A 3-week multicentre randomized controlled trial (ALADIN Study). Diabetologia 1995;38:1425-1433. [PubMed: 8786016]

72. Reljanovic M, Reichel G, Rett K, et al. Treatment of diabetic polyneuropathy with the antioxidant thioctic acid ( $\alpha$-lipoic acid): a two year multicenter randomized double-blind placebo-controlled trial (ALADIN II). Alpha Lipoic Acid in Diabetic Neuropathy. Free Radic Res 1999;31:171-179. [PubMed: 10499773]

73. Ziegler D, Hanefeld M, Ruhnau K, et al. Treatment of symptomatic diabetic polyneuropathy with the antioxidant $\alpha$-lipoic acid: a 7-month multicenter randomized controlled trial (ALADIN III Study). ALADIN III Study Group Alpha-Lipoic Acid in Diabetic Neuropathy. Diabetes Care 1999;22:12961301. [PubMed: 10480774]

74. Ziegler D, Schatz H, Conrad F, Gries F, Ulrich H, Reichel G. Effects of treatment with the antioxidant $\alpha$-lipoic acid on cardiac autonomic neuropathy in NIDDM patients. A 4-month randomized controlled multicenter trial (DEKAN Study) Deutsche Kardiale Autonome Neuropathie. Diabetes Care 1997;20:369-373. [PubMed: 9051389]

75. Ruhnau K, Meissner H, Finn J, et al. Effects of 3-week oral treatment with the antioxidant thioctic acid ( $\alpha$-lipoic acid) in symptomatic diabetic polyneuropathy. Diabet Med 1999;16:1040-1043. [PubMed: 10656234]

76. Ametov AS, Barinov A, Dyck PJ, et al. The sensory symptoms of diabetic polyneuropathy are improved with $\alpha$-lipoic acid: the SYDNEY trial. Diabetes Care 2003;26:770-776. [PubMed: 12610036]

77. Ziegler D, Reljanovic M, Mehnert H, Gries FA. $\alpha$-lipoic acid in the treatment of diabetic polyneuropathy in Germany: current evidence from clinical trials. Exp Clin Endocrinol Diabetes 1999;107:421-430. [PubMed: 10595592]

78. van Beek TA, Montoro P. Chemical analysis and quality control of Ginkgo biloba leaves, extracts, and phytopharmaceuticals. J Chromatogr A 2009;1216:2002-2032. [PubMed: 19195661]

79. Rao SM, Leo GJ, Bernardin L, Unverzagt F. Cognitive dysfunction in multiple sclerosis. I. Frequency, patterns, and prediction. Neurology 1991;41:685-691. [PubMed: 2027484]

80. Amato MP, Ponziani G, Siracusa G, Sorbi S. Cognitive dysfunction in early-onset multiple sclerosis: a reappraisal after 10 years. Arch Neurol 2001;58:1602-1606. [PubMed: 11594918]

81. Napryeyenko O, Sonnik G, Tartakovsky I. Efficacy and tolerability of Ginkgo biloba extract EGb 761 by type of dementia: analyses of a randomised controlled trial. J Neurol Sci 2009;283:224-229. [PubMed: 19286192]

82. Mazza M, Capuano A, Bria P, Mazza S. Ginkgo biloba and donepezil: a comparison in the treatment of Alzheimer's dementia in a randomized placebo-controlled double-blind study. Eur J Neurol 2006;13:981-985. [PubMed: 16930364]

83. Kanowski S, Hoerr R. Ginkgo biloba extract EGb 761 in dementia: intent-to-treat analyses of a 24week, multi-center, double-blind, placebo-controlled, randomized trial. Pharmacopsychiatry 2003;36:297-303. [PubMed: 14663654] 
84. Le Bars PL, Kieser M, Itil KZ. A 26-week analysis of a double-blind, placebo-controlled trial of the ginkgo biloba extract EGb 761 in dementia. Dement Geriatr Cogn Disord 2000;11:230-237. [PubMed: 10867450]

85. Hofferberth B. The efficacy of EGb 761 in patients with senile dementia of the Alzheimer type, a double-blind, placebo-controlled study on different levels of investigation. Hum Psychopharmacol 1994;9:215-222.

86. Le Bars PL, Katz MM, Berman N, Itil TM, Freedman AM, Schatzberg AF. A placebo-controlled, double-blind, randomized trial of an extract of Ginkgo biloba for dementia. North American EGb Study Group. JAMA 1997;278:1327-1332. [PubMed: 9343463]

87. DeKosky ST, Williamson JD, Fitzpatrick AL, et al. Ginkgo biloba for prevention of dementia: a randomized controlled trial. JAMA 2008;300:2253-2262. [PubMed: 19017911]

88. Schneider LS, DeKosky ST, Farlow MR, Tariot PN, Hoerr R, Kieser M. A randomized, double-blind, placebo-controlled trial of two doses of Ginkgo biloba extract in dementia of the Alzheimer's type. Curr Alzheimer Res 2005;2:541-551. [PubMed: 16375657]

89. van Dongen M, van Rossum E, Kessels A, Sielhorst H, Knipschild P. Ginkgo for elderly people with dementia and age-associated memory impairment: a randomized clinical trial. J Clin Epidemiol 2003;56:367-376. [PubMed: 12767414]

90. van Dongen MC, van Rossum E, Kessels AG, Sielhorst HJ, Knipschild PG. The efficacy of ginkgo for elderly people with dementia and age-associated memory impairment: new results of a randomized clinical trial. J Am Geriatr Soc 2000;48:1183-1194. [PubMed: 11037003]

91. Birks J, Grimley Evans J. Ginkgo biloba for cognitive impairment and dementia. Cochrane Database Syst Rev 2007;2:CD003120. [PubMed: 17443523]

92. Birks J, Grimley Evans J. Ginkgo biloba for cognitive impairment and dementia. Cochrane Database Syst Rev 2009;1:CD003120. [PubMed: 19160216]

93. Birks J, Grimley EV, Van Dongen M. Ginkgo biloba for cognitive impairment and dementia. Cochrane Database Syst Rev 2002;4:CD003120. [PubMed: 12519586]

94. Lovera J, Bagert B, Smoot K, et al. Ginkgo biloba for the improvement of cognitive performance in multiple sclerosis: a randomized, placebo-controlled trial. Mult Scler 2007;13:376-385. [PubMed: 17439907]

95. Fisk JD, Pontefract A, Ritvo PG, Archibald CJ, Murray TJ. The impact of fatigue on patients with multiple sclerosis. Can J Neurol Sci 1994;21:9-14. [PubMed: 8180914]

96. Freal JE, Kraft GH, Coryell JK. Symptomatic fatigue in multiple sclerosis. Arch Phys Med Rehabil 1984;65:135-138. [PubMed: 6703889]

97. Lee J, Zhao YLiand X-J. Current evaluation of the milliennium phytomedicine - Ginseng (II): collected chemical entities, modern pharmacology, and clinical applications emanated from traditional Chinese medicine. Curr Med Chem 2009;16:2924-2942. [PubMed: 19689273]

98. Blumenthal M. Asian ginseng: potential therapeutic uses. Adv Nurse Pract 2001;9:26-28. [PubMed: 12416051]

99. Chan TW, But PP, Cheng SW, Kwok IM, Lau FW, Xu HX. Differentiation and authentication of Panax ginseng, Panax quinquefolius, and ginseng products by using HPLC/MS. Anal Chem 2000;72:1281-1287. [PubMed: 10740871]

100. Fuzzati N, Gabetta B, Jayakar K, et al. Determination of ginsenosides in Panax ginseng roots by liquid chromatography with evaporative light-scattering detection. J AOAC Int 2000;83:820-829. [PubMed: 10995108]

101. Wang X, Sakuma T, Asafu-Adjaye E, Shiu GK. Determination of ginsenosides in plant extracts from Panax ginseng and Panax quinquefolius L. by LC/MS/MS. Anal Chem 1999;71:1579-1584. [PubMed: 10221076]

102. Washida D, Kitanaka S. Determination of polyacetylenes and ginsenosides in Panax species using high performance liquid chromatography. Chem Pharm Bull (Tokyo) 2003;51:1314-1317. [PubMed: 14600381]

103. Block KI, Mead MN. Immune system effects of echinacea, ginseng, and astragalus: a review. Integr Cancer Ther 2003;2:247-267. [PubMed: 15035888]

104. Fulder SJ. Ginseng and the hypothalamic-pituitary control of stress. Am J Chin Med 1981;9:112118. [PubMed: 7345916] 
105. Fushimi H, Komatsu K, Isobe M, Namba T. 18S ribosomal RNA gene sequences of three Panax species and the corresponding ginseng drugs. Biol Pharm Bull 1996;19:1530-1532. [PubMed: 8951182]

106. Hiai S, Yokoyama H, Oura H, Yano S. Stimulation of pituitary-adrenocortical system by ginseng saponin. Endocrinol Jpn 1979;26:661-665. [PubMed: 232038]

107. Kennedy DO, Scholey AB. Ginseng: potential for the enhancement of cognitive performance and mood. Pharmacol Biochem Behav 2003;75:687-700. [PubMed: 12895687]

108. Kim SH, Park KS. Effects of Panax ginseng extract on lipid metabolism in humans. Pharmacol Res 2003;48:511-513. [PubMed: 12967598]

109. Maresco A. Double-blind study of multivitamin complex supplemented with ginseng extract. Drugs Exp Clin Res 1996;22:323-329. [PubMed: 9034759]

110. Wiklund IK, Mattsson LA, Lindgren R, Limoni C. Effects of a standardized ginseng extract on quality of life and physiological parameters in symptomatic postmenopausal women: a doubleblind, placebo-controlled trial. Swedish Alternative Medicine Group. Int J Clin Pharmacol Res 1999;19:89-99. [PubMed: 10761538]

111. Kim E, Lovera J, Schaben L, Bourdette D, Whitham R. A single center, randomized, double-blind, placebo-controlled crossover pilot study of the effects of American ginseng on multiple sclerosis fatigue. Neurology 2009;255:A225.

112. Siegel RK. Ginseng abuse syndrome. Problems with the panacea. JAMA 1979;241:1614-1615. [PubMed: 430716]

113. Chan, PC.; Peckham, JC.; Bishop, JB., et al. National Institutes of Health Publication No. 10-5909. 2009. National Toxicology Program technical report on toxicology and carcinogenesis studies of ginseng in $\mathrm{F} 344 / \mathrm{N}$ rats and $\mathrm{B} 6 \mathrm{C} 3 \mathrm{~F} 1$ mice.

114. Yang F, de Villiers WJ, McClain CJ, Varilek GW. Green tea polyphenols block endotoxin-induced tumor necrosis factor-production and lethality in a murine model. J Nutr 1998;128:2334-2340. [PubMed: 9868178]

115. Koh SH, Lee SM, Kim HY, et al. The effect of epigallocatechin gallate on suppressing disease progression of ALS model mice. Neurosci Lett 2006;395:103-107. [PubMed: 16356650]

116. Levites Y, Weinreb O, Maor G, Youdim MB, Mandel S. Green tea polyphenol (-)epigallocatechin-3-gallate prevents N-methyl-4-phenyl-1,2,3,6-tetrahydropyridine-induced dopaminergic neurodegeneration. J Neurochem 2001;78:1073-1082. [PubMed: 11553681]

117. Choi YB, Kim YI, Lee KS, Kim BS, Kim DJ. Protective effect of epigallocatechin gallate on brain damage after transient middle cerebral artery occlusion in rats. Brain Res 2004;1019:47-54. [PubMed: 15306237]

118. Aktas O, Prozorovski T, Smorodchenko A, et al. Green tea epigallocatechin-3-gallate mediates T cellular NF- $\kappa$ B inhibition and exerts neuroprotection in autoimmune encephalomyelitis. J Immunol 2004;173:5794-5800. [PubMed: 15494532]

119. McLarty J, Bigelow RL, Smith M, Elmajian D, Ankem M, Cardelli JA. Tea polyphenols decrease serum levels of prostate-specific antigen, hepatocyte growth factor, and vascular endothelial growth factor in prostate cancer patients and inhibit production of hepatocyte growth factor and vascular endothelial growth factor in vitro. Cancer Prev Res 2009;2:673-682.

120. Shanafelt TD, Call TG, Zent CS, et al. Phase I trial of daily oral polyphenon E in patients with asymptomatic Rai stage 0 to II chronic lymphocytic leukemia. J Clin Oncol 2009;27:3808-3814. [PubMed: 19470922]

121. Brown AL, Lane J, Coverly J, et al. Effects of dietary supplementation with the green tea polyphenol epigallocatechin-3-gallate on insulin resistance and associated metabolic risk factors: randomized controlled trial. Br J Nutr 2009;101:886-894. [PubMed: 18710606]

122. Hsu CH, Tsai TH, Kao YH, Hwang KC, Tseng TY, Chou P. Effect of green tea extract on obese women: a randomized, double-blind, placebo-controlled clinical trial. Clin Nutr 2008;27:363-370. [PubMed: 18468736]

123. Gloro R, Hourmand-Ollivier I, Mosquet B, et al. Fulminant hepatitis during self-medication with hydroalcoholic extract of green tea. Eur J Gastroenterol Hepatol 2005;17:1135-1137. [PubMed: 16148563] 
124. Pedros C, Cereza G, Garcia N, Laporte JR. Liver toxicity of Camellia sinensis dried etanolic extract. Med Clin (Barc) 2003;121:598-599. [PubMed: 14622530]

125. Vial T, Bernard G, Lewden B, Dumortier J, Descotes J. Acute hepatitis due to Exolise, a Camellia sinensis-derived drug. Gastroenterol Clin Biol 2003;27:1166-1167. [PubMed: 14770123]

126. Holick MF. Environmental factors that influence the cutaneous production of vitamin D. Am J Clin Nutr 1995;61:638S-645S. [PubMed: 7879731]

127. Holick MF, Schnoes HK, DeLuca HF. Identification of 1,25-dihydroxycholecalciferol, a form of vitamin D3 metabolically active in the intestine. Proc Natl Acad Sci USA 1971;68:803-804. [PubMed: 4323790]

128. Tanaka Y, DeLuca HF, Omdahl J, Holick MF. Mechanism of action of 1,25dihydroxycholecalciferol on intestinal calcium transport. Proc Natl Acad Sci USA 1971;68:12861288. [PubMed: 4331086]

129. Cranney A, Horsley T, O'Donnell S, et al. Effectiveness and safety of vitamin D in relation to bone health. Evid Rep Technol Assess (Full Rep) 2007:1-235. [PubMed: 18088161]

130. van den Berg H. Bioavailability of vitamin D. Eur J Clin Nutr 1997;51(Suppl 1):S76-S79. [PubMed: 9023488]

131. Adams JS, Liu PT, Chun R, Modlin RL, Hewison M. Vitamin D in defense of the human immune response. Ann NY Acad Sci 2007;1117:94-105. [PubMed: 17656563]

132. Szodoray P, Nakken B, Gaal J, et al. The complex role of vitamin D in autoimmune diseases. Scand J Immunol 2008;68:261-269. [PubMed: 18510590]

133. Correale J, Ysrraelit MC, Gaitan MI. Immunomodulatory effects of vitamin D in multiple sclerosis. Brain 2009;132:1146-1160. [PubMed: 19321461]

134. Smolders J, Damoiseaux J, Menheere P, Hupperts R. Vitamin D as an immune modulator in multiple sclerosis: a review. J Neuroimmunol 2008;194:7-17. [PubMed: 18177949]

135. Munger KL, Levin LI, Hollis BW, Howard NS, Ascherio A. Serum 25-hydroxyvitamin D levels and risk of multiple sclerosis. JAMA 2006;296:2832-2838. [PubMed: 17179460]

136. Munger KL, Zhang SM, O'Reilly E, et al. Vitamin D intake and incidence of multiple sclerosis. Neurology 2004;62:60-65. [PubMed: 14718698]

137. Barnes MS, Bonham MP, Robson PJ, et al. Assessment of 25-hydroxyvitamin D and 1,25dihydroxyvitamin D3 concentrations in male and female multiple sclerosis patients and control volunteers. Mult Scler 2007;13:670-672. [PubMed: 17548449]

138. van der Mei IA, Ponsonby AL, Dwyer T, et al. Vitamin D levels in people with multiple sclerosis and community controls in Tasmania, Australia. J Neurol 2007;254:581-590. [PubMed: 17426912]

139. Soilu-Hanninen M, Airas L, Mononen I, Heikkila A, Viljanen M, Hanninen A. 25-hydroxyvitamin D levels in serum at the onset of multiple sclerosis. Mult Scler 2005;11:266-271. [PubMed: 15957505]

140. Hiremath GS, Cettomai D, Baynes M, et al. Vitamin D status and effect of low-dose cholecalciferol and high-dose ergocalciferol supplementation in multiple sclerosis. Mult Scler 2009;15:735-740. [PubMed: 19383644]

141. Wingerchuk DM, Lesaux J, Rice GP, Kremenchutzky M, Ebers GC. A pilot study of oral calcitriol (1,25-dihydroxyvitamin D3) for relapsing-remitting multiple sclerosis. J Neurol Neurosurg Psychiatry 2005;76:1294-1296. [PubMed: 16107372]

142. Kragt J, van Amerongen B, Killestein J, et al. Higher levels of 25-hydroxyvitamin D are associated with a lower incidence of multiple sclerosis only in women. Mult Scler 2009;15:9-15. [PubMed: 18701572]

143• Ramagopalan SV, Maugeri NJ, Handunnetthi L, et al. Expression of the multiple sclerosisassociated MHC class II allele $H L A-D R B 1 * 1501$ is regulated by vitamin D. PLoS Genet 2009;5:e1000369. Study examining the role of vitamin D on genetic susceptibility in MS found that the expression of the MS-associated MHC class II allele $H L A-D R B 1 * 1501$ appears to be regulated by vitamin D. [PubMed: 19197344]

144. Lemire JM, Archer DC. 1,25-dihydroxyvitamin D3 prevents the in vivo induction of murine experimental autoimmune encephalomyelitis. J Clin Invest 1991;87:1103-1107. [PubMed: 1705564] 
145. Cantorna MT, Humpal-Winter J, DeLuca HF. Dietary calcium is a major factor in 1,25 dihydroxycholecalciferol suppression of experimental autoimmune encephalomyelitis in mice. $\mathbf{J}$ Nutr 2009;129:1966-1971. [PubMed: 10539770]

146. Nashold FE, Miller DJ, Hayes CE. 1,25-dihydroxyvitamin D3 treatment decreases macrophage accumulation in the CNS of mice with experimental autoimmune encephalomyelitis. $\mathbf{J}$ Neuroimmunol 2000;103:171-179. [PubMed: 10696912]

147. Smolders J, Thewissen M, Peelen E, et al. Vitamin D status is positively correlated with regulatory T cell function in patients with multiple sclerosis. PLoS One 2009;4:e6635. [PubMed: 19675671]

148. Correa F, Docagne F, Mestre L, et al. Cannabinoid system and neuroinflammation: implications for multiple sclerosis. Neuroimmunomodulation 2007;14:182-187. [PubMed: 18073512]

149•. Lakhan SE, Rowland M. Whole plant cannabis extracts in the treatment of spasticity in multiple sclerosis: a systematic review. BMC Neurol 2009;9:59. Review of studies evaluating cannabis for spasticity in MS. [PubMed: 19961570]

150. Killestein J, Hoogervorst EL, Reif M, et al. Safety, tolerability, and efficacy of orally administered cannabinoids in MS. Neurology 2002;58:1404-1407. [PubMed: 12011290]

151. Wade DT, Robson P, House H, Makela P, Aram J. A preliminary controlled study to determine whether whole-plant cannabis extracts can improve intractable neurogenic symptoms. Clin Rehabil 2003;17:21-29. [PubMed: 12617376]

152. Zajicek J, Fox P, Sanders H, et al. Cannabinoids for treatment of spasticity and other symptoms related to multiple sclerosis (CAMS study): multicentre randomised placebo-controlled trial. Lancet 2003;362:1517-1526. [PubMed: 14615106]

153. Wade DT, Makela P, Robson P, House H, Bateman C. Do cannabis-based medicinal extracts have general or specific effects on symptoms in multiple sclerosis? A double-blind, randomized, placebocontrolled study on 160 patients. Mult Scler 2004;10:434-441. [PubMed: 15327042]

154. Vaney C, Heinzel-Gutenbrunner M, Jobin P, et al. Efficacy, safety and tolerability of an orally administered cannabis extract in the treatment of spasticity in patients with multiple sclerosis: a randomized, double-blind, placebo-controlled, crossover study. Mult Scler 2004;10:417-424. [PubMed: 15327040]

155. Collin C, Davies P, Mutiboko IK, Ratcliffe S. Randomized controlled trial of cannabis-based medicine in spasticity caused by multiple sclerosis. Eur J Neurol 2007;14:290-296. [PubMed: 17355549]

156. Swank, RL.; Dugan, BB. The Mutliple Sclerosis Diet Book: A Low Fat Diet for the Treatment of MS. Doubleday; NY, USA: 1987.

157. Swank RL. Treatment of multiple sclerosis with low-fat diet. AMA Arch Neurol Psychiatry 1953;69:91-103.

158. Swank RL. Multiple sclerosis: twenty years on low fat diet. Arch Neurol 1970;23:460-474. [PubMed: 5471652]

159. Swank RL, Dugan BB. Effect of low saturated fat diet in early and late cases of multiple sclerosis. Lancet 1990;336:37-39. [PubMed: 1973220]

160 . Swank RL, Goodwin J. Review of MS patient survival on a Swank low saturated fat diet. Nutrition 2003;19:161-162. This study, despite its limitations, reported the longest follow-up of the Swank diet in MS subjects and suggested improved clinical outcome, including survival, in those following a Swank diet low in saturated fat. [PubMed: 12591551]

161. Swank RL, Grimsgaard A. Multiple sclerosis: the lipid relationship. Am J Clin Nutr 1988;48:13871393. [PubMed: 3202088]

162. Das UN. Is there a role for saturated and long-chain fatty acids in multiple sclerosis? Nutrition 2003;19:163-166. [PubMed: 12591552]

163•. Weinstock-Guttman B, Baier M, Park Y, et al. Low fat dietary intervention with omega-3 fatty acid supplementation in multiple sclerosis patients. Prostaglandins Leukot Essent Fatty Acids 2005;73:397-404. This study looked at low-fat dietary intervention with omega-3 FA supplementation in MS patients and suggested that it can have moderate benefits in relapsingremitting MS patients on concurrent disease-modifying therapies. [PubMed: 16099630]

164• Nordvik I, Myhr KM, Nyland H, Bjerve KS. Effect of dietary advice and n-3 supplementation in newly diagnosed MS patients. Acta Neurol Scand 2000;102:143-149. This study looked at the effect 
of dietary advice and omega-3 FA supplementation in newly diagnosed MS patients and, despite a small sample size, showed beneficial effects of the intervention. [PubMed: 10987373]

165. Ghadirian P, Jain M, Ducic S, Shatenstein B, Morisset R. Nutritional factors in the aetiology of multiple sclerosis: a case-control study in Montreal, Canada. Int J Epidemiol 1998;27:845-852. [PubMed: 9839742]

166. Payne A. Nutrition and diet in the clinical management of multiple sclerosis. J Hum Nutr Diet 2001;14:349-357. [PubMed: 11906575]

167. Schwarz S, Leweling H. Multiple sclerosis and nutrition. Mult Scler 2005;11:24-32. [PubMed: 15732263] 


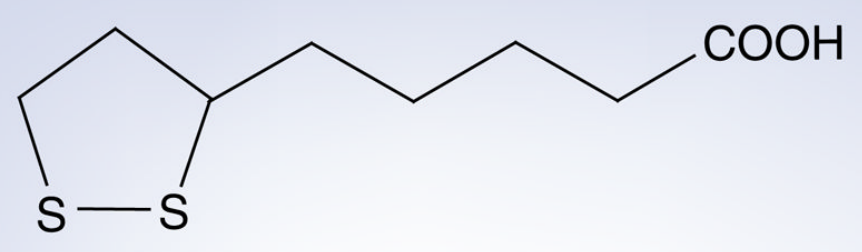

\section{Lipoic acid}

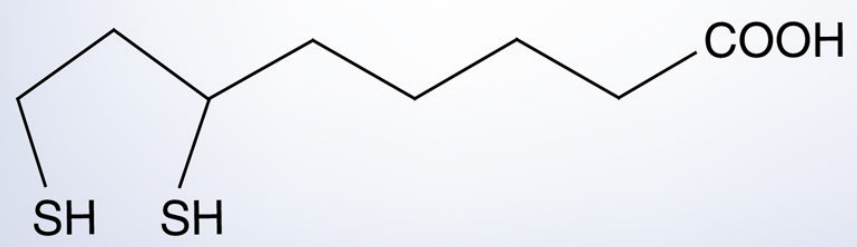

Dihydrolipoic acid

Figure 1.

Lipoic acid and its reduced form, dihydrolipoic acid. 


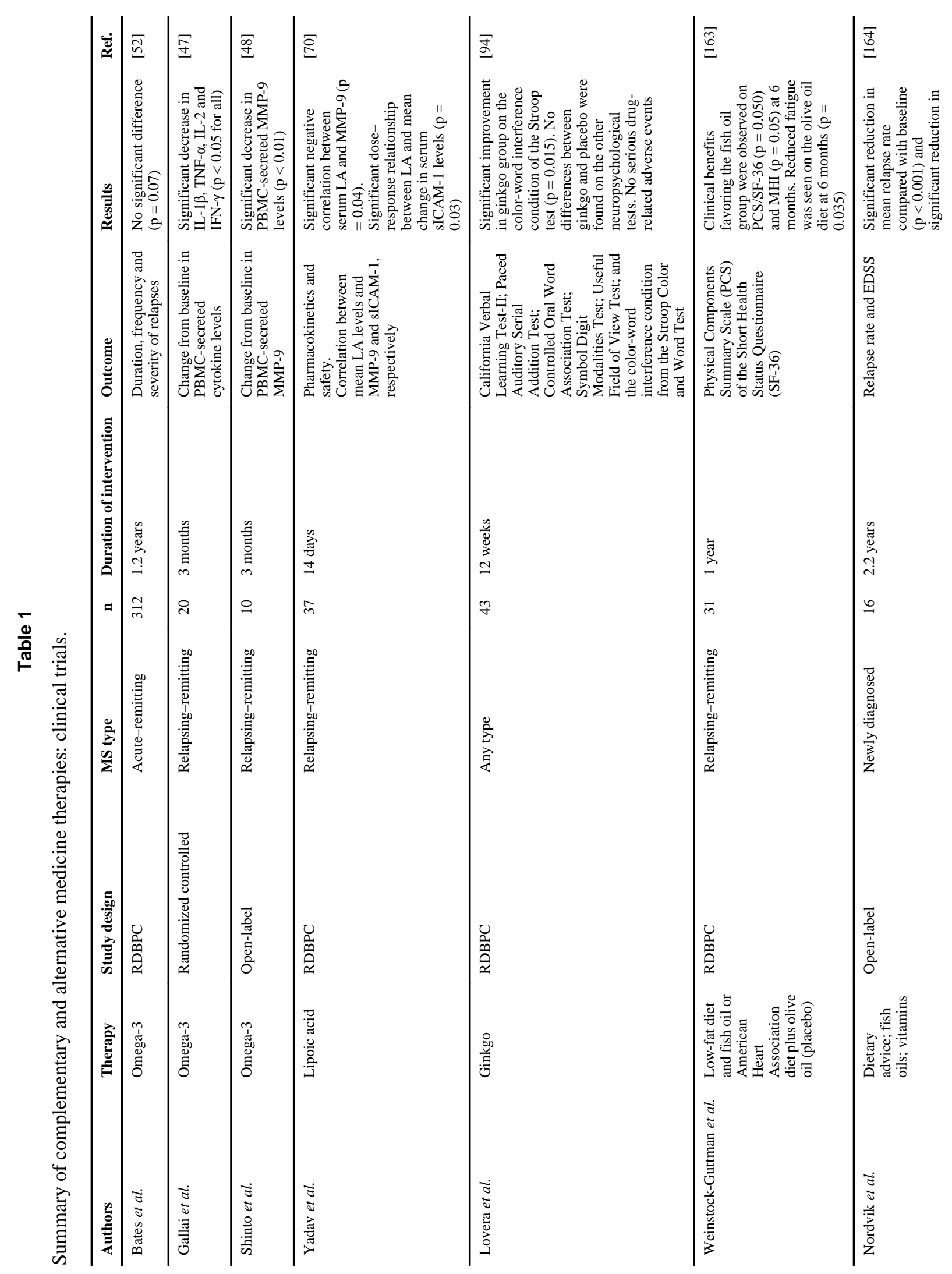

Expert Rev Clin Immunol. Author manuscript; available in PMC 2011 March 1. 
Yadav et al.

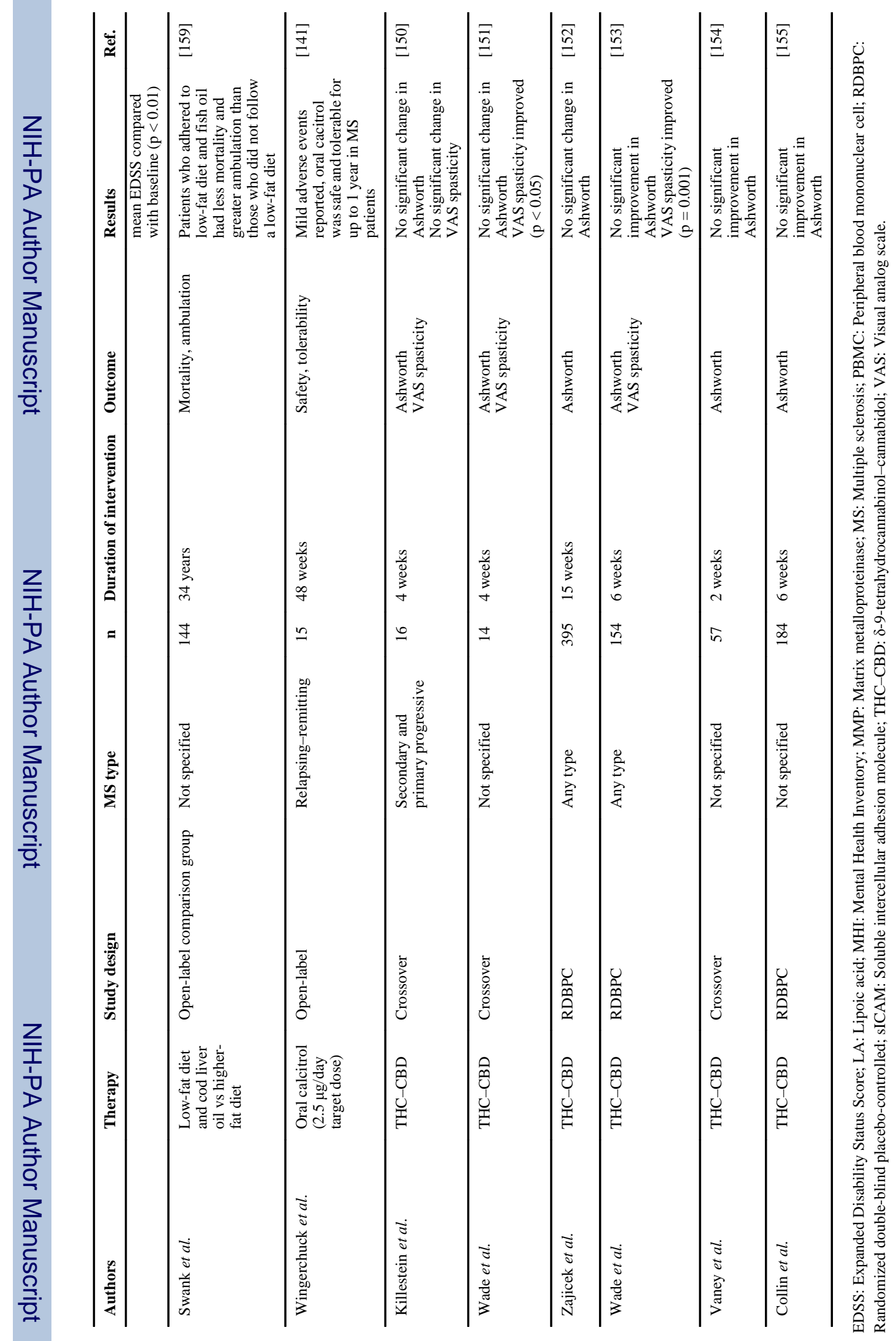

Expert Rev Clin Immunol. Author manuscript; available in PMC 2011 March 1. 